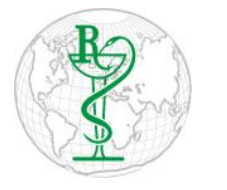

INDO GLOBAL JOURNAL OF

PHARMACEUTICAL SCIENCES

ISSN 2249- 1023

\title{
Psychobiotics in Treatment of Anxiety and Depression
}

Received:
01.03.2019
Accepted:
25.03.2019
Keywords
Gut microbiome;
Probiotics;
Prebiotics;
Psychobiotics;
Gut brain axis.

\author{
Harneet Kaur Dhillon ${ }^{1}$, Pooja Sharma ${ }^{1,2}$, Dinesh Kumar ${ }^{1 *}$ \\ ${ }^{1}$ Sri Sai College of Pharmacy, Manawala, Amritsar-143115, Punjab, India \\ ${ }^{2}$ Department of Pharmaceutical Sciences and Drug Research, Punjabi University Patiala, Punjab, India
}

Address for Correspondence: Dinesh Kumar, dineshkumargndu@gmail.com

Address for Correspondence: Dinesh Kumar, dineshkumargndu@gmail.com

\begin{abstract}
Nowadays, Psychobiotics is an emerging trend. Anxiety and depression is the major serious problems from which almost every person has to suffer. According to the estimation nearly 16.2 million adults have at least one episode of Major depressive disorder and 18\% of the world's population suffered from anxiety disorders. For the effective treatment of the anxiety and depression without producing any kind of side effects psychobiotics grabs the attention. With the administration of the several beneficial strains of the psychobiotics, it helps in the remarkable decrease in the stressful symptoms of anxiety and depression. Several clinical and preclinical studies have been performed for the determination of the effects. In this article, the inter-relationship between the gut microbiome and the brain known as gut brain axis has been explained and the effects for the treatment of anxiety and depression with the administration of probiotics and prebiotics also were explained. (C) 2019 iGlobal Research and Publishing Foundation. All rights reserved.
\end{abstract}

Cite this article as: Dhillon, H.K.; Sharma, P.; Kumar, D. Psychobiotics in treatment of anxiety and depression. Indo Global J. Pharm. Sci., 2019; 9(2Suppl.): $107 . \quad$ DOI:

Indo Global Journal of Pharmaceutical Sciences( ISSN 2249 1023; CODEN- IGJPAI; NLM ID: 101610675) indexed and abstracted in CrossRef (DOI Enabling), UGC CARE Journal List, EMBASE(Elsevier), National Library of Medicine (NLM) Catalog, ResearchGate, Publons, CAS (ACS), Index Copernicus, Google Scholar and many more. For further details, visit http://iglobaljournal.com

This is a special issue as an outcome of 'RAPSCON-2019' sponsored by APTI and organized by Sri Sai College of Pharmacy, Manawala, Amritsar, Punjab, India. Relaxation offered in journal format. 